\title{
MORPHOMETRY OF NECK-SHAFT ANGLE IN DRIED ADULT HUMAN FEMORA OF NORTH INDIAN POPULATION
}

\author{
GURPREET SINGH ${ }^{1}$, GURSHARAN SINGH DHINDSA ${ }^{2 *}$
}

${ }^{1}$ Department of Anatomy, Pt. BD Sharma Post Graduate Institute of Medical Sciences, Rohtak, Haryana, India. ${ }^{2}$ Department of Anatomy, Guru Gobind Singh Medical College, Faridkot, Punjab, India. Email: gursharan91@rediffmail.com

Received: 20 June 2021, Revised and Accepted: 05 August 2021

\section{ABSTRACT}

Objectives: The present study aimed to record the femoral-neck shaft angle was carried out which would be of help to the orthopedicians while carrying out surgical repairs around the hip joint especially in fracture of the neck of femur.

Materials and Methods: A total of 100 North Indian unpaired dry adult human femora (Right-50, Left-50) of unknown sex were studied. Neck-shaft angle (NSA) of the femur was measured with the help of goniometer and measurements were recorded in degrees. The raw data obtained were statistically analyzed. Range, mean, standard deviation, and standard error of mean were determined.

Results: The mean NSA was found to be $127.63^{\circ}+3.48^{\circ}$ (Right $=127.80^{\circ}+3.56^{\circ}$ and $\left.\operatorname{Left}=127.46^{\circ}+3.42^{\circ}\right)$ with a range of $122^{\circ}-137^{\circ}\left(\right.$ Right $=122^{\circ}-137^{\circ}$ and Left $=122^{\circ}-136^{\circ}$ ). No significant difference in values of neck-shaft angle was found in the right and left femora.

Conclusion: The overall goal of this study was to generate information that would be useful for geometric modeling of femora and collecting data which could prove useful for the development of prosthetic implants

Keywords: Femur, Morphometry, Neck-shaft angle.

(C) 2021 The Authors. Published by Innovare Academic Sciences Pvt Ltd. This is an open access article under the CC BY license (http://creativecommons.org/ licenses/by/4.0/) DOI: http://dx.doi.org/10.22159/ajpcr.2021v14i9.42588. Journal homepage: https://innovareacademics.in/journals/index.php/ajpcr

\section{INTRODUCTION}

Femur being the longest and strongest bone of the human body, its length is associated with a striding gait and its strength with weight and muscular forces [1]. It comprises an upper end, shaft and lower end. Proximal part of femur includes head, neck, greater, and lesser trochanters. The angle of the femur formed by the longitudinal axis of the neck and the longitudinal axis of the shaft of femur bone is termed as neck shaft angle. This angle varies with age, sex, race, dominant and non-dominant leg or development of femur. The neck shaft angle generally ranges from $115^{\circ}$ to $140^{\circ}$ at an average of $126^{\circ}$ in adults [2].

The mobility of hip joint is facilitated by the angle, obliquity of the femur within the thigh, which help the knee to be adjacent and inferior to trunk, enabling limb to swing clear of the pelvis $[3,4]$. As the human grows from childhood to adulthood, the neck shaft angle decreases significantly because of the change in body portion and adaptation of the hip joint to vertical posture [5]. The femur neck shaft angle is widest at birth and diminishes gradually until the age of 10 year [6].

The prevalence of hip osteoarthritis, fracture of neck femur and other hip joint ailments are increasing day by day. Nearly half of all hip fractures occur due to femoral neck fractures with the vast majority occurring after simple falls in elderly patients. Non-elderly patients have good bone quality. Due to their high functional demands, preservation of the natural hip mechanics and anatomy is a priority. For replacement procedures, the young age people preclude their candidacy. Only $3-10 \%$ of these fractures take place in younger adults. Dedicated treatment pathway is necessary for the major differences in injury characteristics, physiology, and activity level [7].

Hip axis length, femoral neck shaft axis length, neck shaft angle, and femoral neck width collectively influence the risk of fracture especially in women apart from bone mineral density $[8,9]$.
The morphology of proximal femur is an essential parameter in the design and development of implant because inappropriate implant design and size could affect outcome of the surgery with reported complications such as stress shielding, micro motion, and loosening [10]. Undersized or overhanging femoral implants could lead to altered softtissue tensioning and altered patella femoral stresses [11]. Bony marking such as the head and neck of femur can be used in determination the femoral length when only one fragment of proximal femur is available and the required size of length of neck can be determined to design prosthesis for restoration of normal neck shaft angle [12]. In case of total hip arthroplasty, it is mandatory that the design and dimensions of femoral component should match the anatomy of proximal femur. In clinical practice, if the implant happens to be ill-fitting, hip dislocation and implant fractures are quite common [13].

Most of the Indian orthopedic surgeons have currently felt the need for the modification in implant sizes suitable for Indian population. Therefore, the present study to record the femoral- neck shaft angle was carried out which would be of help to the orthopaedicians while carrying out surgical repairs around the hip joint especially in fracture of the neck of femur. In addition to the orthopedic surgeons this study will be of great help to the anatomists, anthropologists, forensic experts, and radiologist also. Moreover, not much study has been done on femoral neck-shaft angle (NSA) in North Indian population.

\section{MATERIALS AND METHODS}

A total of 100 North Indian unpaired right and left dry adult human femora of unknown sex were studied from teaching collection of the Anatomy department, Guru Gobind Singh Medical College, Faridkot. Out of the total of 100 femora, 50 were of the right side and 50 were of the left side. All the femora was complete and showed normal anatomical features. Bones with any gross abnormality or broken bones were excluded from the study. 
NSA

It is the angle formed between the line joining the center of head of femur to the midpoint of intertrochanteric line and vertical line from the tip of the greater trochanter. The NSA of the femur was measured with the help of a goniometer and recorded in degrees (Fig. 1)

\section{OBSERVATION AND RESULTS}

A total of 100 femora (50 right and 50 left) were studied. Overall range, mean, Standard Deviation, and Standard Error of Mean were 122-137 ${ }^{\circ}$, $127.63^{\circ}, 3.48^{\circ}$, and $0.49^{\circ}$, respectively. Range of femoral NSA in the right and left femur were $122-137^{\circ}$ and $122-136^{\circ}$, respectively. The p-value calculated for this parameter came to be 0.628 and it was nonsignificant (Graph 1). The mean standard deviation, standard error of mean, and distribution on the right and left side of neck-shaft angle are given in Table 1.

\section{DISCUSSION}

The neck shaft angle is one parameter which has been extensively studied by many workers. The angle has been measured on dry bones by goniometer and also by different methods such as roentgenography and computed tomography. The present study was conducted on 100 (50 right and 50 left) dry adult human femora in North Indian Population. The mean NSA was found to be $127.63^{\circ}+3.48^{\circ}$ (Right $=127.80^{\circ}+3.56^{\circ}$ and Left $=127.46^{\circ}+3.42^{\circ}$ ) with a range of $122^{\circ}-137^{\circ}$ (Right $=122^{\circ}-137^{\circ}$ and Left $=122^{\circ}-136^{\circ}$ ).

Ogata et al. [14]measured femoral NSA by roentgenographic technique and compared with those that were measured directly with a goniometer. Neck shaft angle measured by X-ray showed values between $126^{\circ}$ and $137^{\circ}$ and that by goniometer ranged between $121^{\circ}$ and $135^{\circ}$. In a study done by Hoaglund et al. [15] in 294 femora from cadavers of Hong Kong and New England Medical Schools, NSA recorded was $135^{\circ}$ and $134^{\circ}$ in males and females, respectively.

Table 1: Statistical measurements of femoral neck-shaft angle of right and left femur

\begin{tabular}{lllll}
\hline Side & $\begin{array}{l}\text { Range } \\
\text { (degree) }\end{array}$ & $\begin{array}{l}\text { Mean } \\
\text { (degree) }\end{array}$ & $\begin{array}{l}\text { SD } \\
\text { (degree) }\end{array}$ & $\begin{array}{l}\text { SEM } \\
\text { (degree) }\end{array}$ \\
\hline Right & $122-137$ & 127.80 & 3.56 & 0.50 \\
Left & $122-136$ & 127.46 & 3.42 & 0.48 \\
Total & $122-137$ & 127.63 & 3.48 & 0.49 \\
\hline
\end{tabular}

SD: Standard deviation, SEM: Standard error of mean p-value 0.628(non significant)

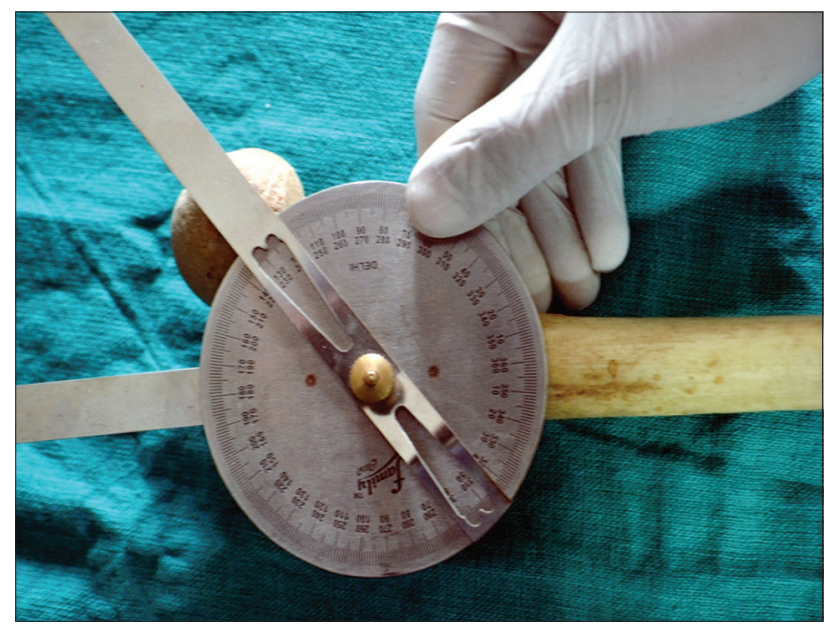

Fig. 1: The measurement of femoral neck-shaft angle with the help of goniometer
Noble et al. [16] found that the neck shaft angle was $124.7^{\circ}$. Prasad et al. [17] studied a total of 171 South Indian unpaired dry femora and noted that neck shaft angle on left side was $126.9^{\circ}$ and that on the right side was $126.5^{\circ}$. Cheng et al. [18] studied femur neck shaft angle of right femur of 64 cadavers. The neck shaft angle in their study was $125^{\circ}$. Maruyama et al. [19] studied 50 male and 50 female skeletons. The mean neck-shaft angle recorded was 125.0․ Silva et al. [20] studied 66 Brazilians human femora, 33 from right and 33 from left limb. In their study, neck shaft angle was $122.55^{\circ}$ on the right and $125.61^{\circ}$ on the left side. De Sousa et al. [21] in the year 2010 studied cervical-diaphyseal angle (CDA) on 110 Brazilian human femur (49 right and 61 left) and noted that it was $132.0^{\circ}+7.2^{\circ}$ on the right side and $131.8^{\circ}+5.2^{\circ}$ on the left side.

Ravichandran et al. [22] did a study on proximal femoral geometry in 578 Indian unpaired femora and noted that the average collodiaphyseal angle was about $126.55^{\circ}$. They concluded that the current available dimensions of Western implants used in the orthopedic surgeries do not match the proximal femoral dimensions of Indians and there was a need for modification of the implants. Gujar et al. [4] studied 250 adult femora in South Indian population and noted that the range of neck shaft angle was between $116^{\circ}$ and $150^{\circ}$ with a mean of $136.3^{\circ}$ and no significant side difference. The neck shaft angle significantly correlated with femoral neck length. In 2013, Kaur et al. [23] studied collodiaphyseal angle in 280 patients by radiography in the North West Indian population. The mean collodiaphyseal angle of the total population on the left side was $121.13^{\circ}+2.44^{\circ}$ (Males $=121.33^{\circ}+2.36^{\circ}$ and Females $=120.16^{\circ}+2.51^{\circ}$ ) and on the right side it was $121.39^{\circ}+2.46^{\circ}$ $\left(\right.$ Males $=121.63^{\circ}+2.41^{\circ}$ and Females $=121.16^{\circ}+2.50^{\circ}$ ). The study concluded that the collodiaphyseal angle does not have significant difference between both the sides and both the genders in the North West Indian population. Khan et al. [24] in the year 2014 studied 250 femora and recorded NSA of femur was $137.1^{\circ}$ (right $137.3^{\circ}$ and left $136.9^{\circ}$ ).

In 2015 Dhivya et al. [25] did study on 158 dry femora, neck shaft angle ranged between $120^{\circ}$ and $145^{\circ}$ with a mean of $134.15^{\circ}$. Ravi et al. [26] recorded NSA of femur was $136.8^{\circ}$ (right $=136.7^{\circ}$ and left $=136.9^{\circ}$ ). Lakati et al. [27]reported that mean femoral NSA was found to be 129.21ํ.Shivashankarappa et al. [28] did study on 457 femurs and noted that the mean neck shaft angle of femur was $138.3+5.67^{\circ},\left(136.2+4.54^{\circ}\right.$ on right side and $140.1+5.43^{\circ}$ on left side). Mukhia et al. [29] in year 2019 conducted a study on 75 femur of both sex and concluded that the femur neck shaft angle of the left femur was significantly higher than that of the right femur $(\mathrm{p}=0.03)$.

The values of NSA in the present study are in consonance with values in previous studies done by Prasad et al. [17] and Ravichandran et al. [22].

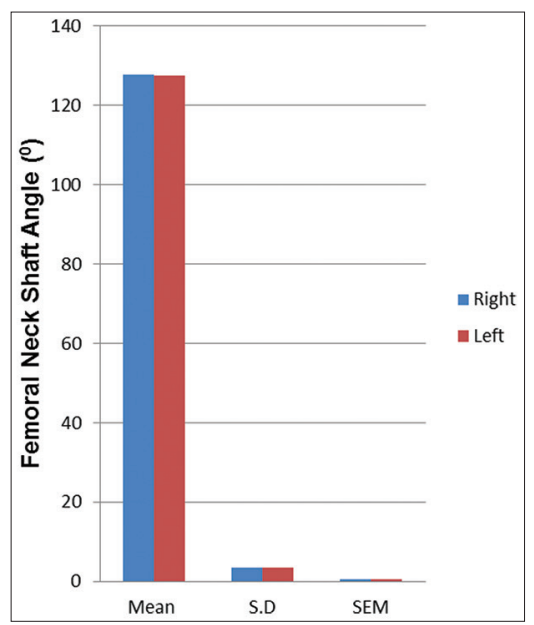

Graph 1: Comparison of parameters of femoral neck-shaft angle of the right and left femur (degree) 
No significant difference was found between the values of right and left side. The difference seen between the values of present study and those recorded by other workers could be explained on the basis of geographic, ethnic, and racial variations.

\section{CONCULSION}

The overall goal of this study was to generate information that would be useful for geometric modeling of femora and collecting data which could prove useful for development of prosthetic implants. In cases, where destruction of femora is extensive, due to trauma or some disease, the data may be helpful for sizing the replacement and reconstructing normal alignment. However, it should be kept in mind, that the present study had a smaller number of femur bones, so it is worthwhile to perform similar study on more number of bones for its theoretical and practical importance in the coming years.

\section{AUTHORS' CONTRIBUTIONS}

Mr. Gurpreet Singh: Conceived the idea of this study, data collection, manuscript writing, and analytical methods.

Dr. Gursharan Singh Dhindsa also conceived the idea of this study, verified the analytical methods, statistical analysis, manuscript writing, and proof reading.

\section{REFERENCES}

1. Standring S. Gray's anatomy. In: Pelvic Girdle, Gluteal Region and Thigh. $41^{\text {st }}$ ed., Ch. 80. London: Churchill Livingstone; 2016. p. 1348-51.

2. Sundar G, Sangeetha V. Morphometric study of human femur. Indian J Med Res Pharm Sci 2018;5:52-5.

3. Moore KL, Dalley AF, Agur AM. Clinically Oriented Anatomy. $6^{\text {th }}$ ed. North Americans: Lippincott and Wilkins; 2013.

4. Gujar SM, Vikani S, Parmar J, Bondre KV.A correlation between femoral neck shaft angle to femoral neck length. Int J Biomed Adv Res 2013;4:295-8

5. Bulandra AM, Gielecki JS, Leciejewska I, Karaszewski P. Digitalimage analysis of the femoral shaft/neck angle in human fetuses. Folia Morphol 2003;62:415-7.

6. Birkenmaier C, Jorysz G, Jansson V, Heimkes B. Normal development of the hip:A geometrical analysis based on planimetric radiography.J Pediatr Orthop B 2010;19:1-8.

7. Isaac B, Vettivel S, Prasad R, Jeyaseelan L, Chandi G. Prediction of the femoral neck-shaft angle from the length of the femoral neck. Clin Anat 1997; 10:318-23.

8. Tuck SP, Rawlings DJ, Scane AC, Pande I, Summers GD, Woolf $\mathrm{AD}$, et al. Femoral neck shaft angle in men with fragility fractures.J Osteoporos 2011;2011:903276.

9. Shrestha A, Ranjit N, Shrestha R. Neck shaft angle of non-articulated femur bones among adults in Nepal. Med J Shree Birendra Hosp
2015;14:1-4

10. Baharuddin MY, Kadir MR, Zulkifly AH, Saat A, Aziz AA, Lee MM. Morphology study of the proximal femur in Malay population. Int $\mathrm{J}$ Morphol 2011;29:1321-5.

11. Gnudi S, Ripamonti C, Lisi L, Fini M, Giardino R, Giavaresi G. Proximal femur geometry to detect and distinguish femoral neck fractures from trochanteric fractures in postmenopausal women. Osteoporos Int 2002;13:69-73.

12. Bidmos MA. Estimation of stature using fragmentary femora in indigenous South Africans. Int J Legal Med 2008;122:293-9.

13. Chowdhary S, Naushaba H, Begum J, Ahmed S, Khan LF, Parash TH, et al. Morphometrical and topographical anatomy of position of nutrient foramen on fully ossified left femur. Delta Med Coll J 2013;1:13-8.

14. Ogata K, Goldsand EM.A simple biplanar method of measuring femoral anteversion and neck shaft angle.J Bone Joint Surg Am 1979;61:846-51.

15. Hoaglund FT, Low WD. Anatomy of the femoral neck and head, with comparative data from Caucasians and Hong Kong Chinese. Clin Orthop Relat Res 1980;152:10-6.

16. Noble PC, Alexander JW, Lindahl LJ, Yew DT, Granberry WM, Tullos HS. The anatomic basis of femoral component design. Clin Orthop Relat Res 1988;235:148-65.

17. Prasad R, Vettivel S, Jeyaseelan L, Isaac B, Chandi G. Reconstruction of femur length from markers of its proximal end. Clin Anat 1996;9:28-33.

18. Cheng XG, Lowet G, Boonen S, Nicholson PH, Brys P, Nijs J, et al. Assessment of the strength of proximal femur in vitro: Relationship to femoral bone mineral density and femoral geometry. Bone 1997;20:213-8.

19. Maruyama M, Feinberg JR, Capello WN, D'Antonio JA. Morphologic features of the acetabulum and femur. Clin Orthop Relat Res 2001;393:52-65.

20. da Silva VJ, Oda JY, Sant'ana DM. Anatomical aspects of the proximal femur of adult Brazilians. Int J Morphol 2003;21:303-8.

21. de Sousa E, Fernandes RM, Mathias MB, Rodrigues MR, Ambram AJ, Babiniski MA. Morphometric study of proximal femur extremity in Brazilians. Int J Morphol 2010;28:835-40.

22. Ravichandran D, Muthukumaravel N, Jaikumar R, Das $H$, Rajendran M. Proximal femoral geometry in Indians and its clinical applications.J Anat Soc India 2011;60:6-12.

23. Kaur P, Mathew S, George U.A study of neck shaft angle in the North West Indian population on radiographs. Int J Basic Med Sci 2013;3:9-15.

24. Khan SM, Saheb SH. Study on neck shaft angle and femoral length of South Indian femurs. Int J Anat Res 2014;2:633-5.

25. Dhivya S, Nandhini V.A study of certain femoral metrics in South Indian population and its clinical importance. Int J Sci Stud 2015;3:132-5.

26. Ravi GO, Saheb SH, Abraham RJ.A morphometric study of femur and its clinical importance. Int J Integr Med Sci 2016;3:341-4.

27. Lakati KC, Ndeleva BM, Mouti N, Kibet J. Proximal femur geometry in the adult Kenyan femur and its implication in orthopaedic surgery. East Afr Orthop J 2017;11:22-7.

28. Shivashankarappa A, Prasad NC, Pavan PH.A study on femur neck shaft angle and its clinical importance. Int J Orthop Sci 2017;3:755-7.

29. Mukhia R, Poudel PP, Bhattarai C, Timsina S. Morphometric study of proximal end of femur of Nepalese people. Nepal J Med Sci 2019;4:9-14. 